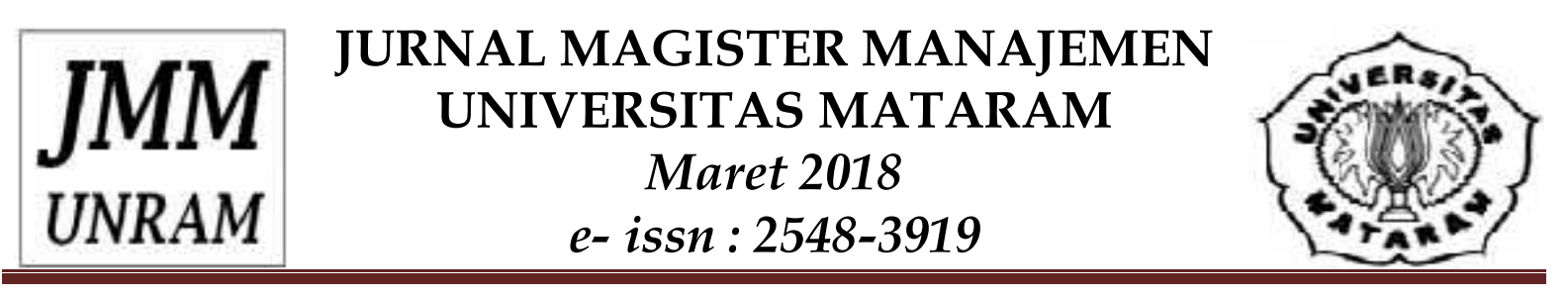

\title{
PENGARUH TIPE BUDAYA ORGANISASI TERHADAP PERILAKU KNOWLEDGE SHARING: PENDEKATAN KONSEP
}

\begin{abstract}
Oleh
Hermanto

ABSTRACT

Resources are central to the existence of any organisation, and among these resources, knowledge is recognised as one of the most important. Knowledge can be categorised as explicit or tacit. Explicit knowledge can be articulated, stored independently, and easily communicated. Conversely, tacitknowledge is embedded deep in people's minds and is not easily shared. Attempts to share can be slow, costly, and uncertain. Although it is acknowledged that there are inherent benefits to tacitknowledge,people, generally, are reluctant to share it because of various barriers. According to prior research,organisational culture is one of the main barriers. This paper proposes a conceptual framework that will facilitate the study of the influence of organisational culture types on tacitknowledge-sharing behaviour.
\end{abstract}

Keywords: Organisational Behaviour, Innovation, Knowledge Management

\section{PENDAHULUAN}

\section{Latar belakang}

Sumber daya (resource) sangat penting bagi keberlanjutan eksistensi organisasi apa pun. Teori berbasis sumber daya (RBV, Resource Based View) mengadopsi pandangan ini sebagai dasar keyakinan (Barney, 1991; Drucker, 2000; Grant, 1996; Penrose, 1959), yakni dari berbagai sumber daya yang ada dalam sebuah organisasi,pengetahuan diakui sebagai pembeda utama dan sangat penting bagi setiap organisasi untuk mempertahankankeunggulan kompetitif (Halawi, Aronson, dan McCarthy, 2005). Drucker (1993) mengatakan bahwa pengetahuan adalah salah satu sumber daya yang sangat berbeda(distinctive) dalam bisnis apa pun, dan lebih jauh disebutkan juga bahwa uang, modal, dan teknologi tidak lagi menjadidasar bergeraknya organisasi (Drucker, 2000). Ditegaskan pula, pengetahuan dan modal intelektual (intellectual capital) adalah kuncisumber kekayaan organisasi dan merupakan penggerak utama pembangunan ekonomi dan sosial (Cantu,Bustani, Molina, dan Moreira, 2009; De la Vega dan Stankosky, 2006). Pengetahuan bisa diklasifikasikan lebih luas menjadi dua jenis: eksplisit dan tacit (Nonaka dan Takeuchi, 1995). Pengetahuan yang bisadiartikulasikan dan disimpan secara independen dan konstruktif, mudah diekspresikan (Nonaka dan Takeuchi, 1995), dandikomunikasikan (Grant, 1996) merupakan cirri yang melekat pada komponen eksplisit sehingga membedakannya dengan tipe pengetahuan lain.Sebaliknya, pengetahuan tacit(tacitknowledge) tertanam jauh di dalam pikiran orang dan merupakan bagian dari pemikiran kognitif danpersepsional. Pengetahuan tacit tidak mudah dibagikan (Wang, Ashleigh, dan Meyer, 2006), dan setiap upaya untukberbagi bisa lambat, mahal, dan tidak pasti (Kogut dan Zander, 1992).

Manajemen pengetahuan (knowledge management) adalah metode untuk menyederhanakan dan meningkatkan proses berbagi, mendistribusikan,membuat, dan 


\section{JMM UNRAM

memahami pengetahuan perusahaan (Nonaka dan Konno, 1998). Di antara banyakkegiatan dalam manajemen pengetahuan, berbagi pengetahuan (knowledge sharing) diakui sebagai yang paling utama (Ford,2001 dalam Al-Alawi, Al-Marzooqi dan Mohammed, 2007). Knowledge sharing sering didefinisikan sebagaiproses mengirim dan menerima pengetahuan antara dan di antara individu, tim dan kelompok,unit organisasi, dan organisasi (Gupta dan Govindarajan, 2000; Klein 2008). Knowledge sharingmendapatkan lebih banyak perhatian dari para peneliti karena potensi manfaat bagi individu danorganisasi (Jonsson dan Kalling, 2007; Yi, 2009) dan sangat penting untuk kesuksesan perusahaan (Davenport danPrusak, 1998). Meskipun diakui bahwa ada manfaat yang melekat pada tacitknowledge, namun secara umumorang enggan membagikannya karena berbagai alasan, seperti system, proses, kepercayaan,motivasi, dan kepemimpinan (Abzari dan Teimouri, 2008), dan budaya organisasi (Al-Alawi et al., 2007;Davenport dan Prusak, 1998; McDermott dan O'Dell, 2001).

Budaya sering dianggap sebagai penghambat utama dari knowledge sharing yang efektif dalam organisasi (Ford danChan, 2003; McDermott dan O'Dell, 2001). Budaya organisasi merupakan keyakinan yang dianut, nilai-nilai,aturan, norma perilaku, artefak, dan asumsi dasar (Schein, 2004, hal. 59).Budaya knowledge sharing bervariasi di dalam dan di antara organisasi (Conelly dan Kelloway, 2003). Lebih jauh Mitchell (2008) menemukan bahwa knowledge sharing yang efektif terjadi dalam organisasidi mana budaya berbagi telah digunakan sebagai norma berinteraksi dalam organisasi. Belum banyak ditemukan kajian tentang pengaruh budaya organisasi terhadap knowledge sharing (Sackmanndan Friesl, 2007), sehingga masih terdapat kesenjangan dalam tubuh pengetahuan tentang pengaruh tipe budaya organisasi pada perilaku berbagi tacitknowledge. Dengan demikian, tujuan dari kerangka kerja konseptual ini adalah menjembatani kesenjangan ini.

\section{Masalah Penelitian}

Pandangan berbasis sumber daya memiliki premis bahwa keberhasilan organisasi bergantung pada bagaimanamenggunakan sumber dayanya secara efektif (Barney, 1991; Drucker, 2000; Grant, 1996; Penrose, 1959), danpengetahuan diakui sebagai salah satu sumber daya yang paling penting (Drucker, 1993). Manajemenpengetahuan (knowledge management, disingkat $\mathrm{KM}$ ) dalam organisasi telah menjadi aktivitas penting (Kingston dan Macintosh, 2000), danberbagi pengetahuan diakui sebagai aktivitas KM yang paling umum (Ford, 2001).

Di antara berbagai faktor yang memfasilitasi knowledge sharing, telah ditunjukkan secara konsisten oleh para peneliti sebelumnya bahwa budaya organisasi merupakan salah satu yang paling berbeda dibandingkan dengan factor lainnya (Abzari dan Teimouri, 2008; AlAlawi et.al., 2007;Chin-Loy dan Mujtaba, 2007; McDermott dan O'Dell, 2001; RománVelázquez, 2005). Manfaat yang melekatknowledge sharing dalam organisasi telah diperdebatkan oleh para ahli dan manajemenpraktisi, namun pada umumnya orang enggan berbagi pengetahuan karena berbagai alasan, dan di antara berbagaialasan yang dikemukakan sebagai factor utama adalah budaya organisasi (Al-Alawi et.al., 2007; Davenport \&Prusak, 1998;McDermott \&O'Dell, 2001). Budaya organisasi seringkali sulit dipahami dan cenderungditerima begitu saja (Schein, 2004). Dengan demikian, masalah penelitian pertama adalah bahwa kebanyakan studi empirismengadopsi pendekatan deskriptif dalam mengidentifikasi budaya organisasi, dan hanya ada beberapa penelitian terbatas itutelahmenggunakan pendekatan diagnostik. Pendekatan diagnostik diharapkan dapat mengurangi tingkatabstraksi dalam menentukan dan memahami budaya organisasi. Karena itu, kerangka kerja konseptualdikembangkan dalam makalah ini didasarkan pada 


\section{JMM UNRAM

pendekatan diagnostik menggunakan penilaian instrument budaya organisasi(OCAI) (Cameron dan Quinn, 2006).

Beberapa studi tentang pengaruh budaya organisasi dan knowledge sharing (Sackmanndan Friesl, 2007) yang sebagian besar diantaranya telah mengadopsi pandangan yang luas dan umum tentang pengetahuantanpa membedakan konsep tacit dan explicit knowledge.Explicitknowledge biasanya tertanam dalam sistem dan proses organisasi dan terlihat dengan jelas di semua jenis dokumen dan database. Sebaliknya, tacitknowledgetertanam di dalam pikiran manusiadan membutuhkan partisipasi aktif dan keinginan dari individu untuk dibagikan (Davenport dan Prusak, 1998; Nonaka and Takeuchi, 1995). Artefak explicit knowedge dapat mengaburkan temuan penelitiansekaligus membuktikan bagaimana perilaku knowledge sharing. Sementara di lain pihak, mungkin hanya sedikit atau tidak ada artefakterkait dengan tacitknowledge.Dalam konteks ini permasalahan akan semakin jelas ketika nilai tacitknowledge sangat tinggi dan dalam jumlah besar ada dalam organisasi (Buckman, 2004; Davenport \&Prusak, 1998;Mooradian, 2005; Smith, 2001).

Dari uraian tentang berbagai persoalan seputar perilaku berbagi tacit dan explicitknowledge, bisa memunculkanisu-isu yang menantangbagi penelitian berikutnya sehingga benefit dari area yang kurang diteliti tersebut tidak dapat disangkal. Konteks kesenjangan peneletian inilah yang menjadi kerangka konseptual bagi premis penelitian ini.

Tujuan dari makalah ini adalah untuk mengembangkan kerangka kerja konseptual untuk menguji pengaruhtipe budaya organisasi pada perilaku berbagi tacitknowledge.

\section{TINJAUAN PUSTAKA}

\section{Knowledge-based View(KBV) dan TacitKnowledge}

Pandangan berbasis pengetahuan (KBV) telah mulai muncul sebagai kerangka teoritis yang kuat dan unik dalam manajemen strategis. Setiap teori manajemen strategis harus menjawab dua pertanyaan: 'Why firms exist?" (Coase, 1937) dan 'Why firms differ?" (Nelson, 1991; Penrose, 1959). Menurut KBV, perusahaan eksis karena memiliki kapabilitas organisasi yang memungkinkan mereka untuk membuat (create), berbagi (share), mengeksploitasi (exploit), dan melindungi (protect) pengetahuan secara lebih efektif dibandingkan dengan perusahaan /organisasi lainnya (Grant \& Baden-Fuller, 2004; Liebeskind, 1996). Perusahaan adalah 'komunitas sosial'yang di dalamnya terkandung dan tersebar berbagai macam pengetahuan diubah menjadi produk dan jasa yang bermanfaat secara ekonomi dengan penerapan seperangkat prinsip pengorganisasian terstruktur (Kogut \& Zander, 1992). Selanjutnya dikatakan Kogut \& Zander (1996) bahwa perusahaan seharusnya dipahami sebagai komunitas sosial yang mengkhususkan diri dalam kecepatan dan efisiensi dalam penciptaan dan transfer pengetahuan.

Mereka (perusahaan) memiliki mekanisme unggul yang membuat mereka lebih baik dalam menghasilkan, mengintegrasikan, dan menerapkan pengetahuan untuk kegiatan bisnis. Dengan demikian, tidak mengherankan bahwa para ahli menganggap pengetahuan menjadi bagian penting untuk menjelaskan keberadaan perusahaan (Hayek, 1988). Dalam $\mathrm{KBV}$, apa yang membuat perusahaan berbeda adalah variasi dalam penerapan manajemen pengetahuan. Masalah mendasar yang dihadapi semua perusahaan adalah cara terbaik memanfaatkan pengetahuan yang dimiliki oleh karyawannya tetapi tidak diberikan kepada satu individu secara keseluruhan (Hayek, 1945). Dengan kata lain, heterogenitas perusahaan merupakan konsekuensi variasi pendekatan pengelolaan dalam meningkatkan 


\section{$J M M$ UNRAM

pengetahuan yang tersebar luas dan tersedia untuk perusahaan (Tsoukas, 1996). Perusahaan yang unggul dalam mengelola pengetahuan mendapatkan keunggulan kompetitif dengan memanfaatkan pengetahuan untuk mendapatkan keuntungan ekonomi. Oleh karena itu, KBV dari manajemen strategis memandang perusahaan sebagai organisasi khusus untuk menaklukkan pasar berdasarkan kemampuan yang lebih baik dalam mengelola pengetahuan dan bersaing satu sama lain bagaimana memanfaatkan pengetahuan secara lebih efektif sehingga mencapai keunggulan kompetitif.

Untuk melaksanakan kegiatan dan menghasilkan barang dan jasa, organisasi membutuhkan sumber daya (resource). Pentingnyasumber daya untuk keberhasilan dan bahkan keberadaan organisasi telah menjadi fokus banyak penelitian (Barney, 1991; Grant, 1996; Penrose, 1959). Grant (1996) merumuskan bahwa KBV (berasal dari Resource-based View) dari suatuorganisasi, menitikberatkan pada pengetahuan sebagai sumber daya perusahaan yang paling strategis. Pandangan ini sesuai dengan pendapat para ahli lainnya (Cantu et.al., 2009; De la Vega dan Stankosky, 2006; Drucker, 2000). Sebagian besar peneliti dan praktisi sependapat bahwa unsure dominan pengetahuan dalam suatu organisasi adalah tacitknowledge(Buckman, 2004; Mooradian, 2005). Smith (2001) menemukan bahwa 90 persen dari pengetahuandi organisasi mana pun melekat dan menyatu dalam kepala orang. Tacitknowledge bersifat personal, spesifik konteks, dan sulit untuk diformalkan dan dikomunikasikankarena bisa merupakan pandangan subyektif, intuisi atau firasat (Nonaka dan Takeuchi, 1995). Polanyi (1962) secara sederhana merangkum tacitknowledge dengan

kalimat 'kita tahu lebih banyak daripada yang bisa kita katakan'. Tacitknowledgeadalahantitesis dari explicitknowledge sehingga tidak mudah dibagikan melalui instrumen konvensional, sepertidokumen, database, sistem, dan proses (Kreiner, 2002). Davenport dan Prusak (1998) berpendapatbahwa pengkodean tacitknowledgesulit dilakukan tetapi nilai substansialnya membuatnya sepadan dengan usaha.Terlepas dari tantangan yang disebutkan oleh para ahli dan praktisi, keputusan untuk fokus hanya pada tacitknowledge, bukan explicitknowledge, kerangka konseptual ini dapat dibenarkan karena kuantitas dan nilai substansial untuk organisasi.

Menurut Hendriks (1999), berbagi pengetahuan menunjukkan hubungan antara setidaknya dua pihak, yakni pemilik pengetahuan dan yang memperoleh pengetahuan. Individu dalam organisasi selalu menciptakan (create) dan share pengetahuan sehingga berbai pengetahuan dianggap sebagai kegiatan yang berlangsung secara otomatis. Knowledgesharingmerupakan proses dinamis yang dimediasi oleh faktor-faktor kompleks yang ada di tingkat organisasi, kelompok, dan individu (Andrews \& Delahaye, 2000; Davenport \& Prusak, 1998).Secara umum, knowledge sharing adalah tindakan membuat pengetahuan tersedia bagi orang lain di dalam organisasi(Abzari dan Teimouri, 2008). Penelitian sebelumnya telah menemukan berbagai faktor yang menghambat ataumemfasilitasi berbagi pengetahuan dalam organisasi. Al-Alawi et.al. (2007) menyatakan bahwa kepercayaan (trust), komunikasi,sistem informasi/teknologi, reward, dan struktur organisasi secara positif terkait dengan knowledge sharing dalam organisasi. Di antara berbagai faktor yang memfasilitasi, budaya organisasitelah diidentifikasi secara konsisten oleh sebagian besar peneliti (Abzari dan Teimouri, 2008; Al-Alawi et.al., 2007; Chin-Loy dan Mujtaba, 2007; McDermot dan O'Dell, 2001; Román-Velázquez, 2005);Namun, sebagian besar peneliti ini menggambarkan budaya organisasi secara abstrak. 


\section{TMURAL MAGISTER MANAJEMEN UNIVERSITAS MATARAM Maret 2018

\section{Budaya Organisasi}

Merujuk pada hasil penelitian sebelumnya, Cameron dan Quinn (2006) mengemukakan bahwa perhatian pada konsepbudaya organisasi mulai serius pada 1980an. Mereka berpendapat bahwa jaminan nilai-nilai yang mendasariasumsi, harapan, dan definisi yang sudah ada berkontribusi pada alasan untuk mengabaikanbudaya organisasi sebagai faktor penting. Argumen (atau asumsi) bahwa kinerja organisasi terkait dengan budaya organisasi tertentu telah menjadi subjek yang menarikdari banyak penelitian dan praktisi (De Long dan Fahey, 2000; McDermott dan O'dell, 2001;Schein, 2004). Perilaku organisasional lebih ditentukan oleh budaya daripada dengan arahan dari seniormanajemen, dan penerapan strategi di banyak organisasi akan terpengaruh jika tidak bersesuaian dengan lingkungan budaya organisasi (Jarnagin dan Slocum, 2007).

Memahami dan mendiagnosis budaya, terutama budaya organisasi, telah menjadi pokok bahasan dengan beragam pandangan dan konspsi. Berbagai teori dan alat telah dipresentasikan oleh para ahli (Cameron dan Quinn, 2006;Schein, 2004). Di antara berbagai teori dan model, terdapat konsep yang dikemukakan oleh Cameron dan Quinn (2006), disebutcompeting values framework $(\mathrm{CVF})$, dan telah banyak digunakan dalam penelitian tentang budaya organisasi (Chin-Loy danMujtaba, 2007; Román-Velázquez, 2005). Premis mendasar dari CVF adalah bahwa organisasi biasanya dapat dikatakan memiliki satu atau kombinasi dari empat jenis budaya: klan (clan), adhokrasi (adhocracy), pasar (market),dan hirarki (hierarchy). Cameron dan Quinn juga mengembangkan OCAI dalam hubungannya dengan CVF. Merekaberpendapat bahwa meskipun versi lama OCAI telah dikembangkan, namun tetap memiliki kemampuan prediktif yang sama dengan versi yang lebih parsimoni terhadap budaya organisasi. CVF dan OCAI telah digunakan di lebih dari 1000organisasi dan telah ditemukan penggunaannya untuk memprediksi kinerja organisasi (Cameron dan Quinn, 2006).Sebagian besar pemimpin mengakui budaya organisasi sebagai kendala yang paling signifikan untuk menciptakan dan memanfaatkanknowledgeassets (De Long dan Fahey, 2000). Milne (2007) mengemukakan bahwa, secara umum karyawantermotivasi untuk sekedar mengakumulasi pengetahuan dalam dirinya dibandingkan berbagi dengan sesama dalam organisasi karena berusaha mempertahankan keunggulan kompetitif. Namun temuan beberapa peneliti menunjukkan bahwa budaya organisasi yang mampu mendorongproses knowledge sharing dapat dikembangkan, antara lain dengan insentif (incentives) yang tepat (Al-Alawi et.al., 2007; McDermott dan O'dell, 2001; Milne, 2007),kepemimpinan (leadership) (Jain, Sandhu dan Sidhu, 2006; Nayir dan Uzunçarsili, 2008), dan teknologi (technology) (Al-Alawi dkk.,2007).

\section{HASIL PENELITIAN SEBELUMNYA}

Hasil penelitian sebelumnya menunjukkan bahwa budaya organisasi mempengaruhi berbagai kegiatan knowledgemanagement (KM), dan salah satu yang paling banyak dikutip adalah knowledge sharing karena merupakan kegiatan utama proses KM dalam organisasi (Chin-Loy dan Mujtaba, 2007; Goh dan Hooper, 2009;Román-Velázquez, 2005; Sveiby dan Simons, 2002). Para ahli telah menggunakan berbagai alat untuk mengidentifikasi ataumendiagnosis budaya organisasi dimana model CVF dari Cameron dan Quinn(2006) sangat dihargai dan digunakan secara luas (Chin-Loy dan Mujtaba, 2007; Helfrich et al., 2007; Hooijberg and Petrock, 1993; Román-Velázquez, 2005).

Kajian yang melihat dampakbudaya organisasi pada perilaku knowledge sharingdalam organisasibelum banyak dilakukan (Abzari dan Teimouri, 2008;Al-Alawi dkk., 2007; Barachini, 2009; Chin-Loy dan Mujtaba, 2007; Goh dan Hooper, 2009; Roma-Velázquez, 


\section{JMM UNRAM

2005; Sveiby dan Simons, 2002), terutama penelitian yang lebih focus pada pengaruh tipe budaya organisasi terhadap perilaku tacitknowledge sharing. Chin-Loy dan Mujtaba (2007) menggunakan CVF untuk menggambarkan type budaya organisasi yang sesuai dengan CVF, menggunakan instrumen penilaian KM (Lawson, 2002 dalam Chin-Loy danMujtaba, 2007) untuk mendeteksi keberadaan aktivitas KM, seperti membuat (creating), menangkap (capturing),mengatur (organizing), menyimpan (storing), menyebarluaskan (disseminating), dan menerapkan (applying) pengetahuan. Penelitian ini terutama menekankan padaefek moderasi budaya organisasi pada hubungan antara KM dan manfaat organisasi melalui pertumbuhan, inovasi, dan keunggulan kompetitif.Chin-Loy dan Mujtaba (2007) menunjukkan bahwa ada hubungan positif antara jenis budaya organisasi dan program $\mathrm{KM}$, dan mereka merumuskan bahwa mengidentifikasi danmemahami budaya organisasi dapat menjembatani kesenjangan dalam memahami pendorong (driver) yang diperlukan untukmenumbuhkan program KM yang sukses. Kerangka konseptual ini berbeda dari temuanChin-Loy dan Mujtaba setidaknya dalam dua aspek: (1) studi melalui kerangka konseptual ini tentang knowledge sharing, bukan pada elemen KM yang lebih luas, dan (2) fokus terutama terletak pada tacitknowledge, bukanknowledge secara keseluruhan sebagai dimensi umum.Al-Alawi et.al. (2007) menggunakan kerangka Gupta dan Govindarajan (2000) untuk mendiagnosis budaya organisasi responden di tempat kerja dan berbagai elemen knowledge sharing yang dipilihdari beberapa sumber. Secara umum, temuan mereka sejalan dengan Chin-Loy dan Mujtaba(2007) bahwa budaya organisasi penting untuk knowledge sharing yang berlaku di tempat kerjameskipun metodologi, alat diagnostik, dan argumen berbeda.

Al-Alawi et al. juga mengidentifikasi dimensi dari kerangka Gupta dan Govindarajan sebagai faktor budaya organisasi, termasuk kepercayaan,komunikasi, sistem informasi, sistem penghargaan, dan struktur organisasi. Sekali lagi, temuan penelitian merekamenyimpulkan bahwa budaya organisasi memiliki hubungan positif dengan knowledge sharing dalamorganisasi. Namun, penelitian Al-Alawi et.al.(2007) tidak memiliki alat diagnostik yang kuat untuk menentukanbudaya organisasi dan dengan demikian bisa menjadi subjek penelitian lebih lanjut sambil mengawasi validitastemuan. Meskipun Gupta dan Govindarajan menyatakan bahwa kerangka kerja mereka didukung oleh penelitian empiris, ada bukti yang cukup dari penggunaan kerangka kerja dalam penelitian ilmiah lainnya untuk membenarkanvaliditas dan reliabilitas. Hal ini berbeda dengan CVF dan alat yang menyertainya, OCAI (Camerondan Quinn, 2006), telah melalui uji validasi oleh beberapa kajian akademis (Cameron dan Quinn,2006; Chin-Loy dan Mujtaba, 2007; Helfrich dkk., 2007; Hooijberg dan Petrock, 1993; Roma-Velázquez, 2005).

Dengan demikian, kerangka kerja konseptual ini berbeda dari Al-Alawi et.al. (2007) setidaknya dalam dua aspek:(1) penggunaan CVF dan OCAI untuk mendiagnosis budaya organisasi, bukan menggunakan kerangka kerja Gupta danGovindarajan (2000), dan (2) fokus hanya pada tacitknowledgesaja, bukanpengetahuan dalam konteks yang lebih luas.Studi empiris lain yang mengidentifikasi jenis budaya pengetahuan menggunakan CVF dan OCAI dan hubungannyadengan praktek KM dilakukan oleh Román-Velázquez (2005). Dalam penelitian ini, Roman-Velázquez menggunakan CVF dan OCAI untuk mendiagnosis budaya organisasi dan menyarankan validitasdan reliabilitas kerangka kerja dengan mengutip berbagai studi (Hooijberg dan Petrock, 1993; O'Neill danQuinn, 1993; Quinn, 2001; Yeung et al., 1991). Temuan penelitian mengungkapkan bahwa KM diterima secara luas dan diimplementasikan pada organisasi yang dikaji. Chin-Loy dan Mujtaba (2007) memperlihatkan temuan yang sama, tetapi keduanya membuat kajian pada organisasi yang sudah memiliki program KM di tempat. Sebaliknya, Roman-Velázquez 


\section{$J M M$ UNRAM

sampai pada kesimpulan berdasarkan tanggapan terhadap survei dan tidak melakukan semacam bias ketika memilih responden. Dengan demikian, Román-Velázquez menyimpulkan bahwa organisasi yang memiliki tipe budaya hierarki memiliki kemungkinan lebih rendah untuk berhasil dalam menerapkan inisiatif KM dibandingkan dengan organisasi tipe budaya klan, pasar, atau adhokrasi. Roman-Velasquez juga menemukan hubungan positifdan signifikan antara budaya organisasi dan budaya unit kerja.

Dengan demikian, kerangka kerja konseptual ini berbeda dari Román-Velázquez (2005) dalam setidaknya duaaspek: (1) studi tentang perilaku knowledge sharing, bukan pada elemen KM yang lebih luas, dan (2) fokus hanya pada tacitknowledge, bukan pada dimensi knowledge secara umum.

Sedikit upaya penelitian yang telah dilakukan untuk mengembangkan ukuran validitas dan reliabilitas perilakuknowledge sharing. Tetapi penelitian Yi (2009) menghasilkan ukuran baru yang sesuai dengan standar psikometrik seperti konsistensi internal, reliabilitas, dan validitas isi. Yi merevisi prosedur pengembangan skala dan secara ketat menyempurnakan skala perilaku knowledge sharing menggunakan pendekatan pilotstudy untuk memurnikan skala. Penelitian Yi berhasil mengidentifikasi konstruk perilaku knowledge sharing yang sangat penting. Taksonomi baru diusulkan yang mengelompokkan perilaku knowledge sharing ke dalamempat dimensi: kontribusi tertulis, komunikasi organisasi, interaksi pribadi, dankomunitas praktisi. Keterbatasan penelitian Yi terletak pada hanya pada responden dari perusahaanhightechnology, dan diketahui bahwa industri semacam itu sangat knowledge intensive. Namun ini bukan merupakan hambatan untuk penggunaan model $Y i$, karena kepentingan pada saat ini sini adalah terkait dengan konstruk perilaku knowledge sharingyang relevan dengan kerangka konseptualberikut.

\section{KERANGKA KONSEPTUAL}

Cameron dan Quinn (2006) mengidentifikasi dua dimensi utama, yaitu (1) flexibility(fleksibilitas) dan discretion (kebijaksanaan) danstability (stabilitas) dan control (control) dan (2) internal focus (fokus internal) dan integrasi (integration) serta fokus eksternal (external focus) dan diferensiasi (differentiation), menghasilkan indikator ke dalam empat kelompok (cluster) utama yakni clan (klan), adhocracy (adhokrasi), hierarchy (hierarki), dan market (pasar). Dimensi dancluster ini membentuk CVF (lihat Gambar 1). OCAI dalam bentuk kuesioner dandapat digunakan untuk mendiagnosis budaya organisasi (Cameron dan Quinn, 2006).

Flexibility \& Discretion

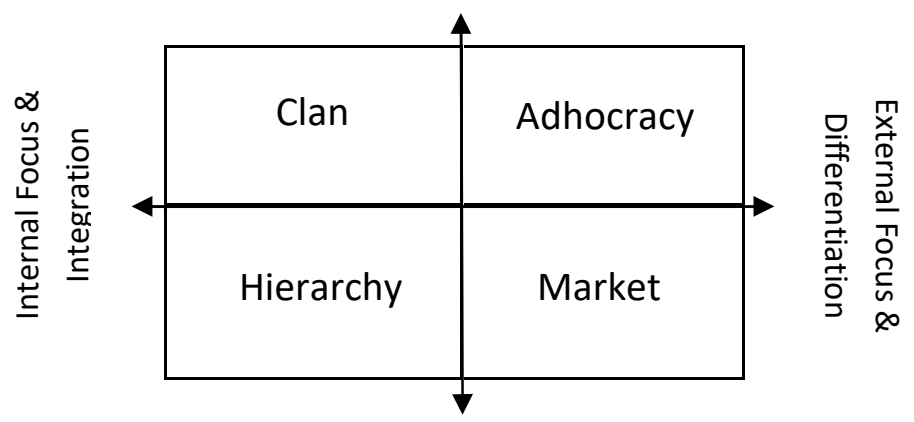

Stability \& Control

Gambar 1 : Competing Values Framework

(Cameron \& Quinn, 2006) 


\section{$J M M$ UNRAM \\ JURNAL MAGISTER MANAJEMEN UNIVERSITAS MATARAM \\ Maret 2018 \\ e- issn : 2548-3919}

Gambar 2 berikut mengilustrasikan model teoritis yang dikembangkan untuk penelitian ini. Premis utama dari model iniadalah setiap jenis budaya dominan dapat mempengaruhi perilaku tacitknowledge sharing secara berbeda. Kerangka ini mengusulkan bahwa perilaku knowledge sharing dapat dibuktikan oleh semua atau kombinasi berikut ini:

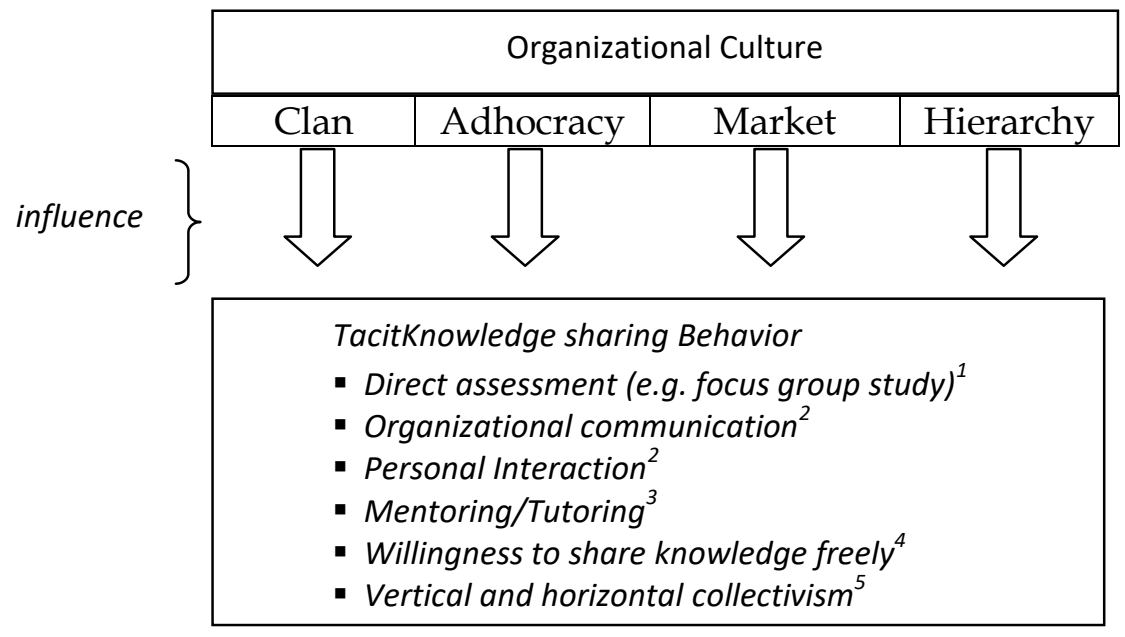

1. Cameron \& Quinn (2006); 2. Yi (2009); 3. Roman-Velazquez (2005)

4. Davenport \& Prusak (2000); 5. Wolfe \& Loraas (2008)

Kerangka ini diusulkan untuk mendiagnosis budaya organisasi dengan bantuan CVF dan OCAI dan untuk menggambarkan profil organisasi sesuai dengan jenis budaya dominan di organisasi responden. Organisasi diharapkan diklasifikasikan sebagai berikut:

1. Budaya klan (clan culture): Tempat yang ramah untuk bekerja di mana orang berbagi banyak hal tentang diri mereka. Karakteristik khas dari suatu organisasi dengan orientasi budaya klan yang dominan adalah kerja tim (team work),program keterlibatan karyawan, komitmen karyawan yang tinggi kepada organisasi dan rekan kerja,dan komitmen perusahaan yang tinggi kepada karyawan. Kepercayaan (trust), menghormati orang, komunikasi yang jujur, dan hubungan yang kohesif (Román-Velázquez, 2005) juga termasuk inti darinilai-nilai organisasi kulturklan.

2. Budaya adhokrasi (adhocracy culture): Organisasi-organisasi yang dominan dengan jenis budaya ini umumnya berbentu organik,dan tidak mekanistik, dan dicirikan oleh tempat kerja dinamis, kreatif dan iklim kewirausahaan sangat Nampak. Karyawan diberdayakan, dan sikap berani mengambil risiko didorong. Kepemimpinan yang efektif adalahvisioner, inovatif, dan berorientasi risiko. Nilai-nilai inti yang dianut karyawan dalam organisasi denganbudaya adhokrasi adalah inovasi dan perubahan, ide-ide baru, pemikiran visioner, dan kemauan untukmencoba konsep baru (Román-Velázquez, 2005). Hubungan kekuasaan atau otoritas terpusat adalahtidak ada dalam budaya jenis ini, sebaliknya kekuatan dan pengetahuan mengalir dari individu keindividu. Berbagi pengetahuan adalah prasyarat untuk sukses.

3. Budaya pasar (market culture): Istilah "pasar" tidak identik dengan fungsi pemasaran ataukonsumen di pasar; melainkan mengacu pada jenis organisasi yang secara eksternalberfokus pada para pemangku kepentingan (stakeholder). Fokus utama organisasi dalam tipe budaya ini adalah melakukantransaksi dengan pemangku kepentingan lain untuk menciptakan keunggulan kompetitif. Kompetitif danproduktivitas membentuk fondasi organisasi yang digerakkan oleh budaya pasar. 
Mencapai kemenangan adalah segalanyadalam tipe organisasi ini (Cameron dan Quinn, 2006), dan daya saing diharapkan menyebar sampai ke tingkat individu. Pengetahuan menjadi proksi untuk kekuasaan, yang membuat terganggunya proses knowledge sharing, terutama tacitknowledge.

4. Budaya hierarki: Secara umum, organisasi yang didominasi oleh tipe budaya ini ditandai olehstruktur hirarki yang banyak dan diformalkan. Diberlakukan prosedur standar untuk mengatur tindakan individu, dan hanya ada sedikit atau bahkan mungkin tidak ada kewenangan diskresi diberikan kepada karyawan. Dengan penekanan pada penguatan peraturan secara tegas, dan kekhawatiran jangka panjang organisasi menyangkut pada stabilitas danprediktabilitas. Budaya hierarki memelihara penggunaan prosedur operasi standar dan contoh praktek terbaik(best practices) dengan memiliki beberapa lapisan posisi vertical dan berbagai unit kerja horizontalrelative beroperasi secara mandiri.Hubungan struktur dan kekuasaan merupakan kendala untuk tacitknowledge sharing pada organisasi ini.

Akan sangat naif untuk percaya bahwa hanya ada empat tipe budaya organisasi (Cameron dan Quinn,2006), namun untuk mengurangi munculnya masalah-masalah validitas dan reliabilitas melalui pengenalan tipe budaya organisasi lainnya, kita perlu untuk selektif memilih tipe budaya organisasi dari sumber referensi lain.

\section{KESIMPULAN}

Selain meningkatnya persaingan secara konvensional (sumber-sumber tradisional), organisasi juga menghadapi ancaman dari sumber non-tradisionalsumber, terutama melalui dunia maya (cyberspace) dan komunikasi seluler. Ketidakmampuan untuk memanfaatkanaset intelektual organisasi dapat berakibat fatal sehingga manajemen harus segera mengambil langkah yang lebih bijaksana untuk menentukanfaktor-faktor yang menghambat aliran pengetahuan dalam organisasi dan mengambil tindakan korektif.

Makalah ini memberikan kontribusi signifikan dalam pengembangan kerangka komprehensif untuk menyelidikipengaruh tipe budaya organisasi pada perilaku tacitknowledge sharing. Banyak penelitian telah membuktikan hubungan budaya organisasi dengan KM, namun belum kajian yang focus pada area hubungan antara tipe tertentu budaya organisasi dengan perilaku tacitknowledge sharing masih sangat sedikit.Dengan demikian kerangka kerja konseptual ini diharapkan menjembatani kesenjangan ini. Sebagai tambahan,penelitian lebih lanjut sangat direkomendasikan pada faktor-faktor lain yang dapat menghambat perilaku tacitknowledge sharingdalam organisasi agar para praktisi memiliki pegangan model komprehensif untuk digunakan dalam bekerja.

\section{DAFTAR PUSTAKA}

Abzari, M. and Teimouri, H. (2008). The Effective Factors on Knowledge sharing in Organizations. The International Journal of Knowledge, Culture and Change Management, 8 (2), 105-113.

Al-Alawi, A.I., Al-Marzooqi, N.Y. and Mohammed, Y.F. (2007). Organizational Culutre and Knowledge Sharing: Critical Success Factors. Journal of Knowledge Management, 11(2), 22-42.

Alavi, M. and Leidner, D.E. (2001). Knowledge Management and Knowledge Management Systems: Conceptual Foundations and Research Issues. MIS Quarterly, 25 (1), 107136. 


\section{JMM UNRAM

Barney, J.B. (1991). Firm Resources and Sustained Competitive Advantage. Journal of Management, 17(1), 99-120.

Barachini, F. (2009). Cultural and Social Issues for Knowledge sharing. Journal of Knowledge Management, 13(1), 98-110.

Buckman, R.H. (2004). Building a Knowledge-Driven Organization. New York: McGrawHill.

Cameron, K. S. and Quinn, R.E. (2006). Diagnosing and Changing Organizational Culture: Based on the Competing Values Framework, Reading MA: Addison-Wesley.

Cantu', F.J., Bustani, A., Molina, A. and Moreira, H. (2009). A Knowledge-based Development Model: The Research Chair Strategy. Journal of Knowledge Management, 13(1), 154-170.

Chin-Loy, C. and Mujtaba, B.G. (2007). The Influence Of Organizational Culture On The Success Of Knowledge Management Practices With North American Companies. International Business \& Economic Research Journal, 6(3), 15-28.

Conelly, C.E. and Kelloway, E.K. (2003). Predictors of Employees' Perceptions of Knowledge sharing Cultures. Leadership \& Organisation Development Journal, 24(5), 294-301.

Davenport, T.H. and Prusak, L. (1998). Working Knowledge: How Organizations Manage What They Know. Boston, MA: Harvard Business School Press.

De la Vega, A.F.R. and Stankosky, M. (2006). Knowledge Management And Innovation: What Must Governments Do To Increase Innovation? Journal of Knowledge Management Practice, 7(4).

De Long, D.W. and Fahey, L. (2000). Diagnosing Cultural Barriers to Knowledge. Academy of Management Executive, 14(4), 113-127.

Drucker, P.F. (1993). Managing for Results. New York: HarperCollins Publishers.

Drucker, P.F. (1999). Management Challenges for the 21st Century. New York: Harper Collins Publishers.

Drucker, P. (2000). Knowledge Work. Executive Excellence, 17(4), 11-12.

Ford, D.P. and Chan, Y.E. (2003). Knowledge sharing in a Multi-cultural Setting: A Case Study. Knowledge Management Research \& Practice, 1, 11-27.

Goh, C.H.T. and Hooper, V. (2009). Knowledge and Information Sharing in a Closed Information Environment. Journal of Knowledge Management, 13(2), 21-34.

Grant, R.M. (1996). Toward a Knowledge-Based Theory of a Firm. Strategic Managemernt Journal. 17(Winter Special), 109-122.

Gupta, A.K. and Govindarajan, V. (2000). Knowledge flows within multinational corporations. Strategic Management Journal, 21(4), 473-496.

Halawi, L., Aronson, J. and McCarthy, R. (2005). Resource-Based View of Knowledge Management for Competitive Advantage. The Electronic Journal of Knowledge Management, 3(2), 75-86.

Helfrich, C.D., Li, Y., Mohr, D.C., Meterko, M. and Sales, A.E. (2007). Assessing and Organizational Culture Instrument Based on the Competing Values Framework: Exploratory and Confirmatory Factor Analyses. Implementation Science, April 2007, 1-14.

Hooijberg, R. and Petrock, F. (1993). On Cultural Change: Using the Competing Values Framework to Help Leaders Execute a Transformational Strategy. Human Resource Management, 32(1), 29-50.

Jain, K.K., Sandhu, M.S. and Sidhu, G.K (2006). Identifying and Overcoming Barriers to Sharing. Knowledge Management Review, 9(4), 6-7. 


\section{$J M M$ UNRAM

Jarnagin, C and Slocum Jr., J.W. (2007). Creating Corporate Cultures through Mythopoetic Leadership. Organizational Dynamics, 36 (3), 288-302.

Jonsson, A. and Kalling, T. (2007). Challenges to Knowledge sharing across National and Intraorganizational Boundaries: Case Studies of IKEA and SCA Packaging. Knowledge Management Research \& Practice, 5, 161-172.

Kingston, J. and Macintosh, A. (2000). Knowledge Management through Multi-perspective Modelling: Representing and Distributing Organizational Memory. Knowledge Based Systems, 13, 121-131.

Klein, J.H. (2008). Some Directions for Research in Knowledge sharing. Knowledge Management Research \& Practice, 6, 41-46.

Kreiner, K. (2002). Tacitknowledge management: the role of artifacts. Journal of Knowledge Management, 6(2), 112-123.

McDermott, R. and O'Dell, C. (2001). Overcoming Cultural Barriers to Sharing Knowledge. Journal of Knowledge Management, 5(1), 76-85.

McElroy, M.W. (2000). Integrating Complexity Theory, Knowledge Management and Organizational Learning. Journal of Knowledge Management, 4 (3), 195-203.

Milne, P. (2007). Motivation, Incentives and Organisational Culture. Journal of Knowledge Management, 11 (6), 28-28.

Mitchell, H. (2008). The Impact of Organisational Change, Knowledge sharing, Culture and Innovation: A Case Study. The International Journal of Knowledge, Culture and Change Management, 8 (1), 71-77.

Mooradian, N. (2005). TacitKnowledge: Philosophical Roots and Role in KM. Journal of Knowledge Management, 9(6), 104-113.

Nayir, D.Z. and Uzunçarsili, U. (2008). A Cultural Perspective on Knowledge Management: The Success Story of Sarkuysan Company. Journal of Knowledge Management, 12(2), 141-155.

Nonaka, I. and Konno, N. (1998). The concept of 'Ba': building a foundation for knowledge creation. California Management Review 40(3), 40-54.

Nonaka, I. and Takeuchi, H. (1995). The Knowledge-Creating Company, NY: Oxford University Press.

Penrose, E.T. (1959). The Theory of the Growth of the Firm. New York: John Wiley.

Polanyi, M. (1962). The Tacit Dimension. New York: Doubleday.

Román-Velázquez, R. (2005). An Empiric Study of Organizational Culture Types and their Relationship with the Success of a Knowledge Management System and the Flow of Knowledge in the U.S.

Government and Nonprofit Sectors, in M. Stankosky (Ed.), Creating the Discipline of Knowledge Management (pp. 66-91). Burlington, MA: Elsevier ButterworthHeinemann.

Sackmann, S.A. and Friesl, M. (2007). Exploring Cultural Impacts on Knowledge sharing Behavior in Project Teams - Results from a Simulation Study. Journal of Knowledge Management, 11(6), 142-156

Schein, E.H. (2004). Organisational Culture and Leadership. San Francisco, CA: Jossey-Bass.

Smith, E.A. (2001). The Role of Tacit and Explicit Knowledge in the Workplace. Journal of Knowledge Management, 5(4), 311-321.

Snowden, D. (2002). Narrative Patterns: Uses of Story in the Third Age of Knowledge Management. Journal of Information and Knowledge Management, 1(1), 1-6.

Sveiby, K. E. and Simons, R. (2002). Collaborative Climate and Effectiveness of Knowledge Work - An Empirical Study. Journal of Knowledge Management, 6(5), 420-433. 


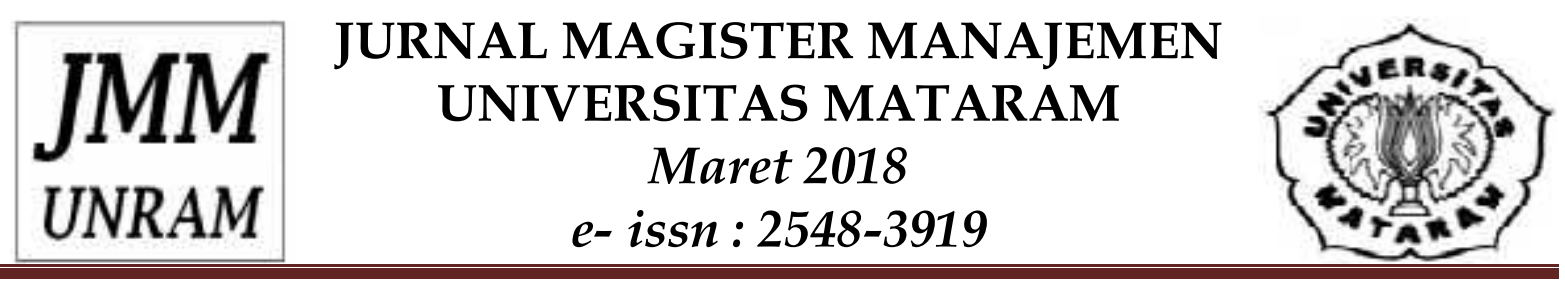

Wang, J., Ashleigh, M. and Meyer, E. (2006). Knowledge sharing and team trustworthiness: it's all about social ties. Knowledge Management Research $\mathcal{E}$ Practice, 4, 175-186.

Yi, J. (2009). A Measure of Knowledge sharing Behavior: Scale Development and Validation. Knowledge Management Research \& Practice, 7, 65-81. 